\title{
Tailoring the Excited-State Intramolecular Proton Transfer (ESIPT) Fluorescence of 2-(2'-Hydroxyphenyl)benzoxazole Derivatives
}

\author{
Jangwon Seo, Sehoon Kim, Sanghyuk Park, and Soo Young Park * \\ Organic Nano-Photonics Laboratory, School of Materials Science \& Engineering, \\ Seoul National University, Seoul 151-744, Korea. E-mail: parksy@snu.ac.kr \\ Received June 10, 2005
}

\begin{abstract}
The excited-state intramolecular proton transfer (ESIPT) fluorescence in the 2-(2'-hydroxyphenyl)benzoxazole (HBO) derivatives with different electron donor and acceptor substituents was studied by spectroscopic and theoretical methods. Changes in the electronic transition, energy levels, and orbital diagrams of HBO analogues were investigated by the semi-empirical molecular orbital calculation and were correlated with the experimental spectral position of ESIPT keto emission. It was found that the presence of substituents, regardless of their nature, resulted in the red-shifted absorption relative to HBO. However, the spectral change of the ESIPT fluorescence was differently affected by the nature of substituent: hypsochromic shift with electron donor and bathochromic shift with electron acceptor.
\end{abstract}

Key Words : Excited-state intramolecular proton transfer (ESIPT), 2-(2'-Hydroxyphenyl)benzoxazole (HBO), Substituent effect, ESIPT fluorescence

\section{Introduction}

Excited-state intramolecular proton transfer (ESIPT) has received considerable attention due to the characteristic four-level photophysical scheme incorporating the ground and excited states of two different tautomers. In the ground state, typical ESIPT molecules preferentially adopt enol (E) form, which is better stabilized by the intramolecular hydrogen-bonding. Upon photoexcitation, however, fast proton transfer reaction from the excited enol ( $\left.E^{*}\right)$ occurs to give the excited keto $\left(\mathrm{K}^{*}\right)$ tautomer in a subpicosecond time scale. After decaying to the ground state, keto $(\mathrm{K})$ form reverts to the original enol form via reverse proton transfer. Different absorbing $\left(\mathrm{E} \rightarrow \mathrm{E}^{*}\right)$ and emitting $\left(\mathrm{K}^{*} \rightarrow \mathrm{K}\right)$ molecular species in this ESIPT cycle normally result in the total exclusion of self-absorption and the large Stokes' shifted keto emission. ${ }^{1-6}$ Based on these unique and beneficial photophysical properties, ESIPT molecules are gaining interest for potential applications in organic light emitting diodes, ${ }^{3}$ photopatterning, ${ }^{4}$ chemosensor, ${ }^{5}$ proton transfer laser, ${ }^{6}$ and photostabilizer. ${ }^{7}$ Fine control of the functional substituents as well as the molecular structure of core ESIPT unit is primarily demanded for specific applications. ${ }^{8-10}$

Among various ESIPT-active molecular structures, 2-(2'hydroxyphenyl)benzoxazole (HBO) has been most often investigated due to its structural simplicity and facile chemical modification. ${ }^{11,12}$ Thus the photophysical mechanism and ESIPT kinetics ${ }^{13-17}$ of azole and benzazole derivatives including HBO have been largely elucidated. Nevertheless, the practically important spectral tuning of keto emission by different electron donor and acceptor substituents in HBO derivatives has not been systematically pursued so far.

In this paper, we have synthesized seven different HBO derivatives by incorporating diethylamino or methoxy group

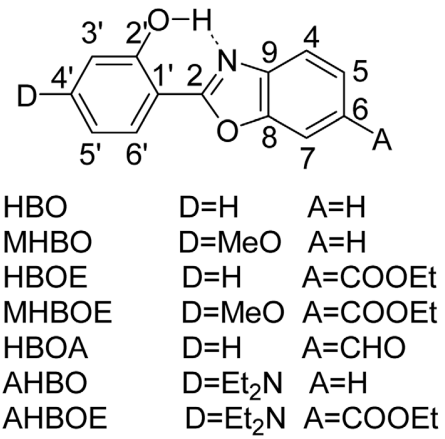

Chart 1. Molecular structures of HBO derivatives.

as electron donor, aldehyde or ethylester group as electron acceptor at 4'- and 6-position of HBO skeleton, respectively (see Chart 1). Changes in the electronic transition, energy levels and orbital diagrams of these HBO analogues were investigated by the semi-empirical molecular orbital (MO) calculation and were correlated with the experimental fluorescence spectra mainly consisting of ESIPT keto emission.

\section{Experimental Section}

Materials. The benzoxazole rings in HBO derivatives of Chart 1 were prepared by the oxidative cyclization of Schiff bases, which were synthesized in-situ from the derivatized salicylaldehyde and 2-aminophenol in acetic acid. ${ }^{18,19} \mathrm{Six}$ HBO derivatives except HBOA in Chart 1 were simply synthesized by this one-step benzoxazole synthesis in acceptable yields. For HBOA, acetic acid 2-(6-methyl-benzoxazol-2-yl)-phenyl ester was first synthesized and sequentially transformed into HBOA via bromination followed by the reaction with hexamethylenetetramine (HMTA), and subsequent oxidation and deprotection. Chemical structures of 
the synthesized $\mathrm{HBO}$ derivatives were identified by ${ }^{1} \mathrm{H}$ NMR, GC-MS and elemental analysis.

2-(2-Hydroxy-phenyl)-benzoxazole $(\mathrm{HBO})^{20}$ Yield = 49\%; ${ }^{1} \mathrm{H}$ NMR (CDCl 3 , ppm) 11.48 (s, $\left.1 \mathrm{H}\right), 8.04$ (dd, $J=$ 7.9, $1.7 \mathrm{~Hz}, 1 \mathrm{H}), 7.71-7.75(\mathrm{~m}, 1 \mathrm{H}), 7.59-7.63(\mathrm{~m}, 1 \mathrm{H})$, 7.36-7.48 (m, 3H), $7.13(\mathrm{dd}, J=8.2,0.9 \mathrm{~Hz}, 1 \mathrm{H}), 7.02(\mathrm{t}, J=$ $7.6 \mathrm{~Hz}, 1 \mathrm{H}$ ); $\mathrm{m} / \mathrm{z}$ (EI) calcd for $\mathrm{C}_{13} \mathrm{H}_{9} \mathrm{NO}_{2}, 211$, found 211; Anal. Calcd for $\mathrm{C}_{13} \mathrm{H}_{9} \mathrm{NO}_{2}$ : C, 73.92; $\mathrm{H}, 4.29 ; \mathrm{N}, 6.63$. Found: C, 74.08; H, 4.32; N, 6.56.

2-(2-Hydroxy-4-methoxy-phenyl)-benzoxazole (MHBO $)^{21}$ Yield $=6 \% ;{ }^{1} \mathrm{H}$ NMR $\left(\mathrm{CDCl}_{3}, \mathrm{ppm}\right) 11.66(\mathrm{~s}, 1 \mathrm{H}), 7.93(\mathrm{~d}, J$ $=8.8 \mathrm{~Hz}, 1 \mathrm{H}), 7.67-7.70(\mathrm{~m}, 1 \mathrm{H}), 7.56-7.60(\mathrm{~m}, 1 \mathrm{H}), 7.34-$ $7.37(\mathrm{~m}, 2 \mathrm{H}), 6.58-6.64(\mathrm{~m}, 2 \mathrm{H}), 3.87$ (s, 3H); m/z (EI) calcd for $\mathrm{C}_{14} \mathrm{H}_{11} \mathrm{NO}_{3}$, 241, found 241; Anal. Calcd for $\mathrm{C}_{14} \mathrm{H}_{11} \mathrm{NO}_{3}$ : C, 69.70; H, 4.60; N, 5.81. Found: C, 69.87; H, 4.66; N, 5.89 .

2-(2-Hydroxy-phenyl)-benzoxazole-6-carboxylic acid ethyl ester (HBOE) Yield $=36 \%$; ${ }^{1} \mathrm{H}$ NMR $\left(\mathrm{CDCl}_{3}, \mathrm{ppm}\right) 11.33$ (s, $1 \mathrm{H}), 8.31(\mathrm{~d}, J=1.5 \mathrm{~Hz}, 1 \mathrm{H}), 8.14(\mathrm{dd}, J=8.4,1.5 \mathrm{~Hz}$, $1 \mathrm{H}), 8.06(\mathrm{dd}, J=7.9,1.7 \mathrm{~Hz}, 1 \mathrm{H}), 7.76(\mathrm{~d}, J=8.3 \mathrm{~Hz}, 1 \mathrm{H})$, 7.49 (t, $J=7.8 \mathrm{~Hz}, 1 \mathrm{H}), 7.14(\mathrm{dd}, J=8.4,1.1 \mathrm{~Hz}, 1 \mathrm{H}), 7.04$ (t, $J=7.5 \mathrm{~Hz}, 1 \mathrm{H}), 4.44(\mathrm{q}, 2 \mathrm{H}), 1.45(\mathrm{t}, 3 \mathrm{H}) ; \mathrm{m} / \mathrm{z}$ (EI) calcd for $\mathrm{C}_{16} \mathrm{H}_{13} \mathrm{NO}_{4}, 283$, found 283; Anal. Calcd for $\mathrm{C}_{16} \mathrm{H}_{13} \mathrm{NO}_{4}$ : C, 67.84; H, 4.94; N, 4.94. Found: C, 67.85; H, 4.70; N, 5.11 .

2-(2-Hydroxy-4-methoxy-phenyl)-benzoxazole-6-carboxylic acid ethyl ester (MHBOE) Yield $=22 \%$; ${ }^{1} \mathrm{H}$ NMR $\left(\mathrm{CDCl}_{3}, \mathrm{ppm}\right) 11.50(\mathrm{~s}, 1 \mathrm{H}), 8.26(\mathrm{~d}, J=1.5 \mathrm{~Hz}, 1 \mathrm{H}), 8.11$ $(\mathrm{dd}, J=8.4,1.5 \mathrm{~Hz}, 1 \mathrm{H}), 7.94(\mathrm{~d}, J=9.0 \mathrm{~Hz}, 1 \mathrm{H}), 7.70(\mathrm{~d}, J$ $=8.2 \mathrm{~Hz}, 1 \mathrm{H}), 6.63-6.60(\mathrm{~m}, 2 \mathrm{H}) 4.43(\mathrm{q}, 2 \mathrm{H}), 3.88(\mathrm{~s}, 3 \mathrm{H})$, $1.44(\mathrm{t}, 3 \mathrm{H}) ; \mathrm{m} / \mathrm{z}$ (EI) calcd for $\mathrm{C}_{17} \mathrm{H}_{15} \mathrm{NO}_{5}, 313$, found 313; Anal. Calcd for $\mathrm{C}_{17} \mathrm{H}_{15} \mathrm{NO}_{5}$ : C, 65.17; H, 4.83; N, 4.47. Found: C, 65.18; H, 4.87; N, 4.34.

2-(2-Hydroxy-phenyl)-benzoxazole-6-carbaldehyde $(\mathrm{HBOA}))^{19}$ Yield $=5 \% ;{ }^{1} \mathrm{H}$ NMR $\left(\mathrm{CDCl}_{3}, \mathrm{ppm}\right) 11.27(\mathrm{~s}$, $1 \mathrm{H}), 10.12(\mathrm{~s}, 1 \mathrm{H}), 8.14(\mathrm{~s}, 1 \mathrm{H}), 8.08$ (dd, $J=7.8,1.6 \mathrm{~Hz}$, $1 \mathrm{H}), 7.96(\mathrm{dd}, J=8.2,1.4 \mathrm{~Hz}, 1 \mathrm{H}), 7.87(\mathrm{~d}, J=8.0 \mathrm{~Hz}, 1 \mathrm{H})$, 7.51 (t, $J=7.1 \mathrm{~Hz}, 1 \mathrm{H}), 7.15$ (dd, $J=8.4,0.6 \mathrm{~Hz}, 1 \mathrm{H}), 7.06$ (t, $J=7.6 \mathrm{~Hz}, 1 \mathrm{H}) ; \mathrm{m} / \mathrm{z}$ (EI) calcd for $\mathrm{C}_{14} \mathrm{H}_{9} \mathrm{NO}_{3}, 239$, found 239; Anal. Calcd for $\mathrm{C}_{14} \mathrm{H}_{9} \mathrm{NO}_{3}$ : C, 70.29; H, 3.79; N, 5.86. Found: C, 70.56; H, 3.92; N, 5.53.

2-(4-Diethylamino-2-hydroxy-phenyl)-benzoxazole (AHBO) Yield $=10 \% ;{ }^{1} \mathrm{H}$ NMR $\left(\mathrm{CDCl}_{3}, \mathrm{ppm}\right) 11.46(\mathrm{~s}$, $1 \mathrm{H}), 7.80(\mathrm{~d}, J=8.6 \mathrm{~Hz}, 1 \mathrm{H}), 7.62(\mathrm{~d}, J=8.0 \mathrm{~Hz}, 1 \mathrm{H}), 7.52$ $(\mathrm{d}, J=8.0 \mathrm{~Hz}, 1 \mathrm{H}), 7.24-7.34(\mathrm{~m}, 2 \mathrm{H}), 6.32-6.36(\mathrm{~m}, 2 \mathrm{H})$, 3.42 (q, 4H), $1.22(\mathrm{t}, 6 \mathrm{H}) ; \mathrm{m} / \mathrm{z}$ (EI) calcd for $\mathrm{C}_{17} \mathrm{H}_{18} \mathrm{~N}_{2} \mathrm{O}_{2}$, 282, found 282; Anal. Calcd for $\mathrm{C}_{17} \mathrm{H}_{18} \mathrm{~N}_{2} \mathrm{O}_{2}$ : C, 72.32; $\mathrm{H}$, $6.43 ; \mathrm{N}, 9.92$. Found: C, 72.58; H, 6.58; N, 10.20.

2-(4-Diethylamino-2-hydroxy-phenyl)-benzoxazole-6carboxylic acid ethyl ester (AHBOE) Yield $=17 \%$; ${ }^{1} \mathrm{H}$ NMR $\left(\mathrm{CDCl}_{3}, \mathrm{ppm}\right) 11.31(\mathrm{~s}, 1 \mathrm{H}), 8.20(\mathrm{~d}, J=1.5 \mathrm{~Hz}, 1 \mathrm{H}), 8.06$ $(\mathrm{dd}, J=8.2,1.4 \mathrm{~Hz}, 1 \mathrm{H}), 7.81(\mathrm{~d}, J=9.0 \mathrm{~Hz}, 1 \mathrm{H}), 7.61(\mathrm{~d}, J$ $=8.4 \mathrm{~Hz}, 1 \mathrm{H}), 6.37(\mathrm{dd}, J=9.0,2.4 \mathrm{~Hz}, 1 \mathrm{H}), 6.30(\mathrm{~d}, J=2.6$ $\mathrm{Hz}, 1 \mathrm{H}), 4.42(\mathrm{q}, 2 \mathrm{H}), 3.43(\mathrm{q}, 4 \mathrm{H}), 1.43(\mathrm{t}, 3 \mathrm{H}), 1.23(\mathrm{t}$, $6 \mathrm{H}) ; \mathrm{m} / \mathrm{z}$ (EI) calcd for $\mathrm{C}_{20} \mathrm{H}_{22} \mathrm{~N}_{2} \mathrm{O}_{4}, 354$, found 354; Anal. Calcd for $\mathrm{C}_{20} \mathrm{H}_{22} \mathrm{~N}_{2} \mathrm{O}_{4}$ : C, 67.78; H, 6.26; N, 7.90. Found: C, $67.99 ; \mathrm{H}, 6.37 ; \mathrm{N}, 8.09$.
Methods. ${ }^{1} \mathrm{H}$ NMR spectra were recorded on a JEOL JNM-LA300 (300 MHz) in $\mathrm{CDCl}_{3}$ solutions. Mass spectra were measured on a JMS AX505WA by EI mode. Elemental analysis was carried out with CE instrument EA1110. UVVis absorption and fluorescence emission spectra were recorded on the HP 8452-A and Shimadzu RF-500 spectrofluorophotometer, respectively. Cyclic voltammetry (CV) experiments were performed with Princeton Applied Research Potentiostat/Galvanostat Model 273A. All measurements were carried out at room temperature with a conventional three-electrode configuration consisting of platinum working electrode, platinum counter electrode, and $\mathrm{Ag} / \mathrm{Ag}^{+}$reference electrode. The solvent in all experiments was dichloromethane, and the supporting electrolyte was $0.05 \mathrm{M}$ tetrabutylammonium hexafluoroborate. $\mathrm{HOMO}$ was estimated from $\mathrm{CV}$ potentials with $50 \mathrm{mV} / \mathrm{s}$ of scan rate using ferrocene as standard. LUMO was derived from the relationship $E_{\mathrm{g}}=$ HOMO-LUMO, where $E_{\mathrm{g}}$ was obtained from optical spectroscopy. Fluorescence quantum yields were determined relatively by comparison with 9,10diphenylantharacenc in cyclohexane as a reference for AHBO and AHBOE. ${ }^{22}$

Semi-empirical MO calculation was implemented by Hyperchem $^{\mathrm{R}}$ package. Molecular geometry was optimized with PM3 method to give energy levels and orbital diagrams. Configuration interaction (CI) with 41 configurations was applied to the calculated absorption maxima. In order to properly correlate the experimental values with calculated ones in gas phase, absorption and emission spectra in nonpolar cyclohexane solution were measured and analyzed. Absorption maxima of enol (E) and keto (K) tautomers were separately and differently assessed in this work. For enol, absorption maxima could be assigned to the longest wavelength band. For keto, however, emission maxima instead of absorption had to be compared with calculated absorption maxima due to the transient nature of the keto tautomer.

\section{Results and Discussion}

Synthesis of HBO derivatives in Chart 1 was carried out by the ring-forming condensation reaction between the derivatized salicylaldehyde and 2-aminophenol in the presence of lead(IV) acetate in glacial acetic acid as reported earlier. ${ }^{18,19}$

Calculated absorption maxima for the enol and keto tautomers are plotted in Figures 1(a) and (b), respectively, against those experimentally observed in a series of HBO compounds. It is clearly noted from Figure 1a that the experimental as well as the calculated enol (E) absorption maxima of the substituted HBO compounds are all redshifted compared to those of HBO. In particular, AHBO and AHBOE, which employ strongly electron donating amino group, show a large shift in absorption maxima. Effect of the electron donating strength is well demonstrated by the considerable spectral shift between AHBO and MHBO. On the other hand, HBOE and HBOA with different electron 

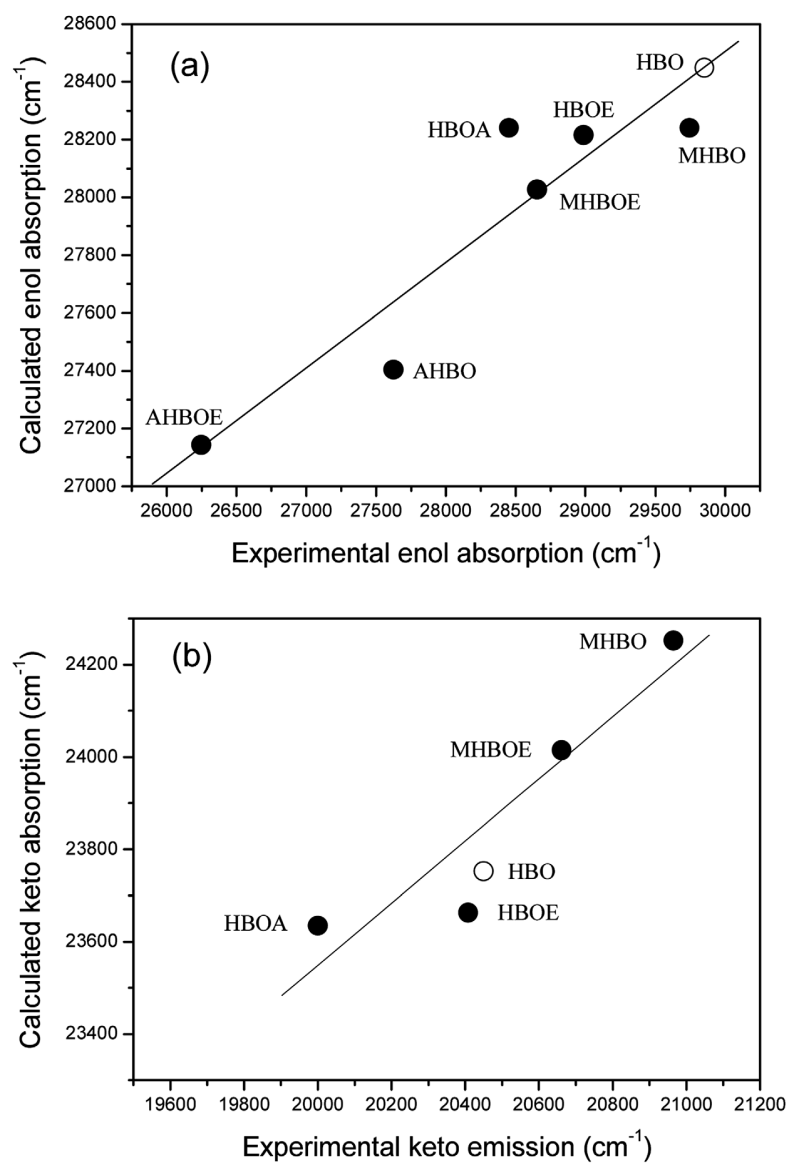

Figure 1. (a) Plot of calculated absorption maxima (wavenumbers $v\left(\mathrm{~cm}^{-1}\right)$ ) of enol (E) tautomer in gas phase $v s$. experimental absorption maxima in cyclohexane solution. (b) Plot of calculated absorption maxima of keto $(\mathrm{K})$ tautomer in gas phase $v s$. experimental emission maxima in cyclohexane solution.

acceptors show similar spectral position probably due to the small difference of acceptor strength. MHBOE, which integrates both electron donor and acceptor substituents in a molecule, shows much red-shifted absorption due to the push-pull dipolar property, when compared to MHBO and HBOE. As shown in Figure 1a, calculated values of the absorption maxima and their dependency on the nature of substituents are in good correlation with the experimental ones. Calculated absorption maxima for the keto (K) tautomer are compared with the experimental keto emission, as shown in Figure 1b, where AHBO and AHBOE were not included due to the absence of a discernable keto emission (vide infra).

Figure 2a shows experimental HOMO and LUMO energy levels in enol tautomer, which were obtained by cyclic voltammetry and optical spectroscopy. It has long been known that mesomeric effects of either electron donating or accepting substituents result in the decrease of electronic transition energy with consequent bathochromic shift in the absorption and emission bands. ${ }^{23}$ This happens because $\Delta$

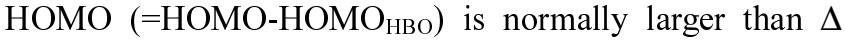

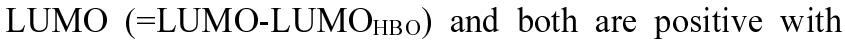
electron donor substituent, while $\Delta \mathrm{HOMO}$ is smaller than $\Delta$ (a)

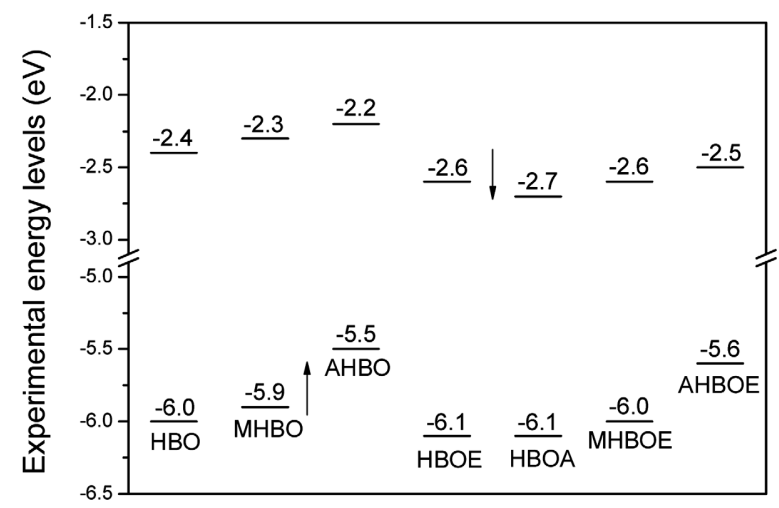

(b)

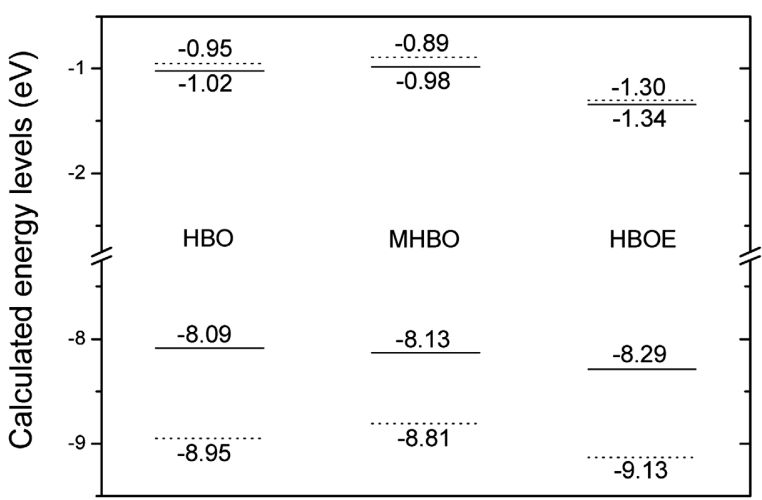

Figure 2. (a) Experimental HOMO and LUMO energy levels (eV) of enol (E) tautomers obtained by cyclic voltammetry and optical spectroscopy, and (b) calculated HOMO and LUMO energy levels $(\mathrm{eV})$ of enol (E) (dotted) and keto $(\mathrm{K})$ (solid) tautomers in HBO, $\mathrm{MHBO}$, and HBOE.

LUMO and both are negative with electron acceptor substituent. ${ }^{23}$ These variations of energy levels caused by mesomeric effect is fully consistent with those of all enol (E) tautomers, as shown in Figure 2a, and can be directly applied to explanation of the red-shifted enol absorption in substituted HBO derivatives compared to HBO shown in Figure 1a. However, as displayed in the calculated HOMO and LUMO energy levels for the keto tautomers of representative compounds (HBO, MHBO, and HBOE) in Figure $2 b$, mesomeric effect of the substituent group must work differently for keto $(\mathrm{K})$ emission particularly with the 4'-donor substituent (vide infra for discussion). Specifically, in the tautomer of MHBO, $\Delta$ LUMO is positive but $\Delta$ HOMO is negative, resulting in the characteristic hypsochromic shift shown in Figure 1b. It is worth noting that this blue-shifted keto emission is unusual and peculiar considering a red-shifted enol absorption brought about by the same substituents.

Fluorescence spectra of HBO compounds in chloroform solution are shown in Figure 3. In the weakly polar and aprotic chloroform solution, the long wavelength emission from keto $(\mathrm{K})$ tautomer is observed above $450 \mathrm{~nm}$ in a series of HBO compounds except AHBO and AHBOE. For AHBO and AHBOE containing strong electron donor substituent, however, the predominant enol (E) emission is observed at $382 \mathrm{~nm}$ and $421 \mathrm{~nm}$, respectively. Particularly, AHBO 


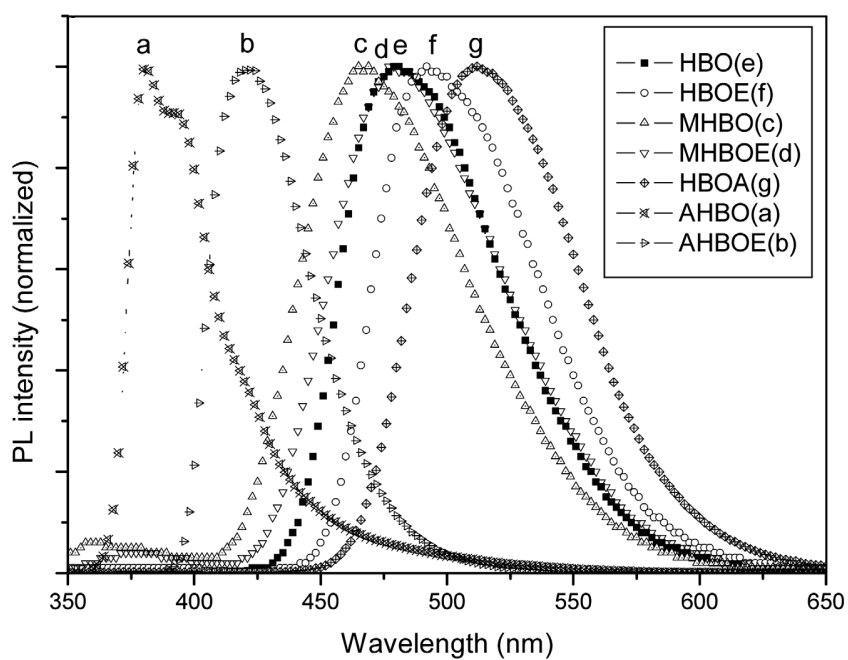

Figure 3. Normalized photoluminescence (PL) spectra of HBO derivatives in chloroform solution.

shows an unusually long-tailed emission band at longer wavelength presumably due to the small fraction of keto emission. ${ }^{24}$ Dual emission from enol (at 350-400 nm) and keto $(>450 \mathrm{~nm})$ forms is shown for MHBO and MHBOE which incorporate moderate electron donor substituent. On the other hand, single exclusive keto $(\mathrm{K})$ emission is observed for $\mathrm{HBO}, \mathrm{HBOE}$ and $\mathrm{HBOA}$ which lack the electron donor substituent. With respect to the spectral position of keto (K) emission, HBOE and HBOA show the red-shifted emission by $11 \mathrm{~nm}$ and $31 \mathrm{~nm}$ compared to that of HBO, while MHBO shows the blue-shifted emission by $15 \mathrm{~nm}$. This peculiar spectral trend depending on the nature of substituents is well consistent with the theoretical calculation as shown in Figure 1b, which can be explained in terms of the $\pi$-electron density at the substituent position by using the calculated orbital diagrams of enol and keto tautomers (see Figure 4). For the electron acceptor substituent, mesomeric effect seems to be effectively developed by the large $\pi$-electron density at carbon 6 for both enol and keto forms. In contrast, for the electron donor substituent, $\pi$ electron density at carbon 4' of keto tautomer in the ground state is extremely lower than that for enol (see Figure 4). That is, in the case of keto tautomer, the absence of $\pi$ electrons at carbon 4' brings about little contribution of mesomeric effect of the 4'-substituent groups. Consequently, rather than the mesomeric effect, the negative inductive effect of methoxy group is likely to contribute to the lowering of HOMO level, resulting in the hypsochromic shift of keto emission. Combining the principles of blueshifted keto emission for electron donor and red-shifted one for electron acceptor, spectral position of MHBOE keto emission located between those of MHBO and HBOE is well rationalized. It is also seen in Figure 3 that the keto emission of HBOA is located at longer wavelength compared to HBOE. It is speculated that the aldehyde group gives more contribution to conjugation by $\pi$-delocalization with benzoxazole ring than the ester group, as manifested by the Yukawa and Tsuno's constants. ${ }^{25}$

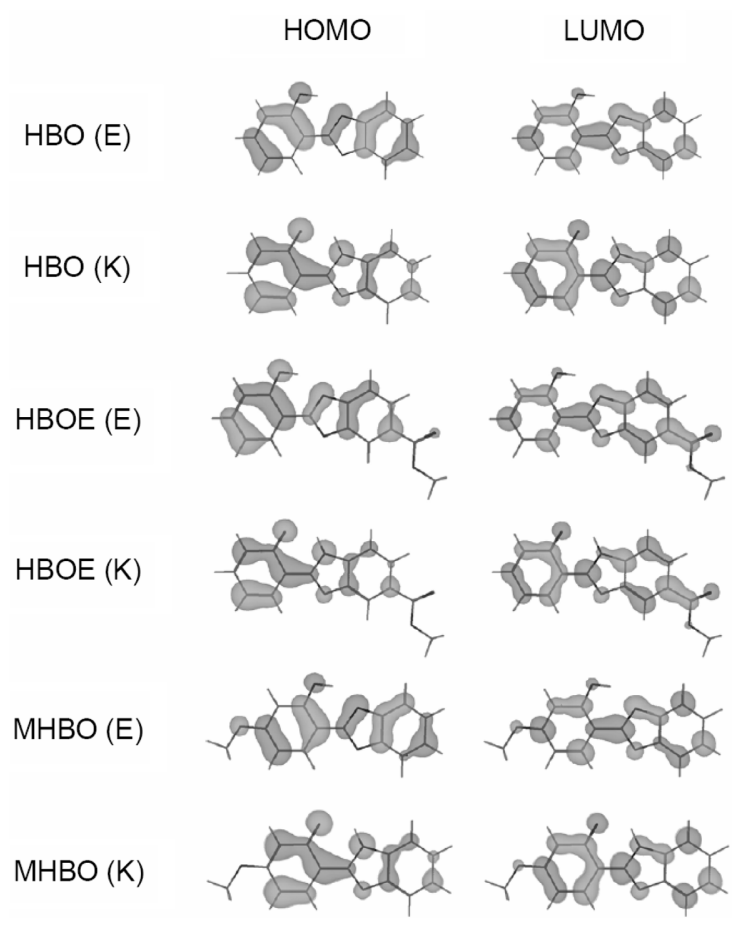

Figure 4. Orbital diagrams of enol and keto tautomer in HBO, HBOE, and MHBO.

\section{Conclusion}

The spectral change of the ESIPT keto emission in the 4'donor and 6-acceptor substituted HBO derivatives showed specific dependence on the nature of substituents: hypsochromic shift with electron donor and bathochromic shift with electron acceptor. This color tuning rule of ESIPT fluorescence was successfully explained by the MO calculation results in terms of the electronic transition, energy levels and orbital diagrams. It was also found that the 6-acceptor substituent has a positive effect on the ESIPT fluorescence while the 4'-donor substituent tend to limit the keto emission.

Acknowledgment. This work was supported by the Ministry of Science and Technology of Korea through National Research Laboratory (NRL) program awarded to Prof. Soo Young Park. We are grateful for the instrumental support from the equipment facility of CRM-KOSEF, Korea University.

\section{References}

1. Abou-Zied, O. K.; Jimenez, R.; Thompson, E. H. Z.; Millar, D. P.; Romesberg, F. E. J. Phys. Chem. A 2002, 106, 3665.

2. Choi, J. R.; Jeoung, S. C.; Cho, D. W. Bull. Korean Chem. Soc. 2003, 24, 1675.

3. Kim, S.; Jang, D. W.; Park, S. Y.; Kim, K.; Jin, J.-I. Bull. Korean Chem. Soc. 2001, 22, 1407.

4. Kim, S.; Park, S. Y. Adv. Mater. 2003, 15, 1341.

5. Tong, H.; Zhou, G.; Wang, L.; Jing, X.; Wang, F.; Zhang, J. Tetrahedron Lett. 2003, 44, 131. 
6. Acuña, A. U.; Costela, A.; Muñoz, J. M. J. Phys. Chem. 1986, 90, 2807.

7. Keck, J.; Kramer, H. E. A.; Port, H.; Hirsch, T.; Fischer, P.; Rytz, G. J. Phys. Chem. 1996, 100, 14468.

8. Chou, P. T.; Martinez, M. L.; Clements, J. H. J. Phys. Chem. 1993, 97, 2618.

9. Klymchenko, A. S.; Demchenko, A. P. J. Am. Chem. Soc. 2002, 124,12372

10. Hillebrand, S.; Segala, M.; Buckup, T.; Correia, R. R. B.; Horowitz, F.; Stefani, V. Chem. Phys. 2001, 273, 1.

11. Mordzinski, A.; Grabowska, A.; Kuhnle, W.; Krowszynski, A. Chem. Phys. Lett. 1983, 101, 291.

12. Kauffman, J. M.; Bajwa, G. S. J. Heterocyclic. Chem. 1993, 30, 1613.

13. Segala, M.; Domingues Jr., N. S.; Livotto, P. R.; Stefani, V. J. Chem. Soc., Perkin Trans. 1999, 2, 1123.

14. Doroshenko, A. O.; Posokhov, E. A.; Verezubova, A. A.; Ptyagina, L. M. J. Phys. Org. Chem. 2000, 13, 253.

15. Doroshenko, A. O.; Posokhov, E. A.; Verezubova, A. A.; Ptyagina, L. M.; Skripkina, V. T.; Shershukov, V. M. Photochem. Photobiol. Sci. 2002, 1, 92.

16. Rampey, M. E.; Halkyard, C. E.; Williams, A. R.; Angel, A. J.; Hurst, D. R.; Townsend, J. D.; Finefrock, A. E.; Beam, C. F.;
Studer-Martinez, S. L. Photochem. Photobiol. 1999, 70(2), 176.

17. Ouyang, J.; Ouyang, C.; Fujii, Y.; Nakano, Y.; Shoda, T.; Nagano, T. J. Heterocyclic Chem. 2004, 41, 359.

18. Kim, S.; Park, S. Y. Bull. Korean Chem. Soc. 1999, $20,473$.

19. Seo, J.; Kim, S.; Park, S. Y. J. Am. Chem. Soc. 2004, 126, 11154.

20. LeGourriérec, D.; Kharlanov, V. A.; Brown, R. G.; Rettig, W. J. Photochem. Photobiol. A: Chem., 2000, 130, 101.

21. Brewster, K.; Chittenden, R. A.; Harrison, J. M.; Inch, T. D.; Brown. C. J. Chem. Soc., Perkin Trans. 1 1976, 12, 1291.

22. Hamal, S.; Hirayama, F. J. Phys. Chem. 1983, 87, 83.

23. Klessinger, M.; Michl, J. Excited States and Photochemistry of Organic Molecules; VCH: New York, 1995.

24. AHBO shows no distinct keto emission, but a long-tailed emission band in aprotic solvent compared to that in protic solvent. In contrast, such a long tailing at longer wavelength was not observed in the ethyl-blocked AHBO as non-ESIPT model compound, irrespective of solvents, whose fluorescence quantum yield (54.2\%) was 9 times higher than that $(5.9 \%)$ of AHBO. This idea is further supported by the high fluorescence quantum yield (93.1\%) of AHBOE, which exhibits only the enol emission band without any long tailing.

25. Nagaoka, S.; Nakamura, A.; Nagashima, U. J. Photochem. Photobiol. A 2002, 54, 23. 